\title{
Auditory and visual distance estimation after active or passive visual deprivation
}

\author{
ROBERT I. REYNOLDS \\ Fordham University at Lincoln Center, New York, New York
}

\begin{abstract}
Subjects estimated distances between themselves and a familiar sound source immediately after being blindfolded and after $75 \mathrm{~min}$ of visual deprivation. One group of 15 undergraduate subjects spent 75 min sitting passively, and 15 subjects in a second group were verbally guided to actively move through their natural environment. The passive group showed no improvement in accuracy of distance estimation. Subjects with active experience showed a significant $(p<.001)$ increase in accuracy, giving estimations superior even to those made while sighted. While the positive effects of active movement upon visual adaptation are well known, the dramatic adaptation to short-term visual deprivation found in this experiment is unique. It is proposed that, during training, one constructs a superior analogic representation of the spatial world. This hypothesis is supported by the fact that visual as well as auditory judgments improve during training.
\end{abstract}

Stimulus input achieved through self-generated movement appears necessary for the development of accurate visually guided behavior (e.g., Held \& Hein, 1963). Reafferent stimulation also consistently produces greater adaptation to prismatic displacement than does passive stimulation (e.g., Held \& Bossom, 1961). It has been argued (e.g., Coren, 1966) that self-generated movement is generally the most effective (though not the only) means of providing error feedback to the direction and extent of prismatic displacement. Unfortunately, experimental studies on reafferent effects upon perceptual development and learning come exclusively from the visual domain. While it is generally believed that adaptation involves a perceptual recalibration of the higher centers used to interpret perceptual input, this is difficult to demonstrate conclusively when investigating vision alone.

Some evidence suggests that perceptual learning based upon reafferent input also occurs in the auditory domain. For example, Curtis and Winer (1969) found that the ambulatory blind are more accurate than are the homebound blind or sighted persons in detecting changes in sound intensity. Supposedly, the ambulatory blind develop compensatory auditory skills because of feedback in response to their activities. Jones (1975) suggests that the lack of sensory compensation found in some studies (e.g., Bross \& Borenstein, 1982; Fisher, 1964) is due to erroneously grouping together the ambulatory and homebound blind.

The present experiment tests the beneficial effects of reafference upon the learning of auditory distance judgments. Subjects were asked to make judgments as to the absolute distance of a familiar sound source before and after being blindfolded for 75 min. Extending Held's find-

The author expresses his gratitude to Thanos Kalimeris for his comments and assistance in collecting data. Reprint requests may be sent to Robert I. Reynolds, Division of the Social Sciences, Room 916, Fordham University at Lincoln Center, New York, NY 10023. ings to the auditory domain, it is hypothesized that active experience during visual deprivation will lead to more accurate judgments of auditory distances than will passive experience. The training period of $75 \mathrm{~min}$ was determined, after a number of pilot studies, to be the shortest duration to produce an effect.

\section{METHOD}

Student volunteers from Nasson College were randomly assigned to 1 of 2 groups: 15 subjects were assigned to the "active" group, and 15 to the "passive" group. Each group consisted of 8 men and 7 women.

During the initial phase of the experiment, all 30 subjects judged nine distances between themselves and the experimenter on the basis of vision alone. Stimulus presentation was in a concrete block hallway. The nine stimulus distances used in all phases of the experiment were 5 , $6,7,15,17,19,23,28$, and $38 \mathrm{ft}$. Each observer judged these distances in a different random order. The subjects were encouraged to estimate each distance to the nearest half foot. At no time during the experiment did the subjects receive feedback from the experimenter in regard to the accuracy of their distance judgments.

Immediately following the initial sighted phase, each subject was blindfolded and asked to judge the distance between him/herself and a taperecorded voice of the experimenter asking, "How far away am I?" The recording was taped in an echo-free room. With their blindfolds remaining in place, the subjects in the passive group then retired to a soundproof room for $75 \mathrm{~min}$ of easy-listening music, and the subjects in the active group were talked through a variety of activities on campus. The training in the active group involved visiting familiar areas, walking up and down stairs and across campus, socializing with students, and, in general, trying to live as actively as possible.

Following this 75-min phase, the subjects in both groups again estimated the distances blindfolded. Finally, in the last phase, they again made solely visual judgments of the same distances.

\section{RESULTS}

As might be expected, there is a greater magnitude of error at greater distances. When combining all distances and conditions, the correlation between magnitude of error and distance was $+.83(p<.001)$ for the active group and $+.71(p<.005)$ for the passive group. It fol- 
Table 1

Percentage of Errors Across All Distances

\begin{tabular}{|c|c|c|c|c|}
\hline Condition & $M$ & $S D$ & Mdn & $t$ tests \\
\hline \multicolumn{5}{|c|}{ Auditory Judgments } \\
\hline $\begin{array}{l}\text { Passive } 2 \\
\text { Passive } 3\end{array}$ & $\begin{array}{l}28.83 \\
26.46\end{array}$ & $\begin{array}{l}7.92 \\
4.55\end{array}$ & $\begin{array}{l}27.00 \\
24.37\end{array}$ & $t(14)=1.06$, n.s. \\
\hline $\begin{array}{l}\text { Active } 2 \\
\text { Active } 3\end{array}$ & $\begin{array}{r}30.12 \\
8.60\end{array}$ & $\begin{array}{r}10.03 \\
4.69\end{array}$ & $\begin{array}{r}26.13 \\
6.30\end{array}$ & $t(14)=4.40, p<.001$ \\
\hline $\begin{array}{l}\text { Active 2-3 } \\
\text { Passive 2-3 }\end{array}$ & $\begin{array}{r}21.52 \\
2.37\end{array}$ & & & $t(28)=3.32, p<.005$ \\
\hline \multicolumn{5}{|c|}{ Visual Judgments } \\
\hline $\begin{array}{l}\text { Passive } 1 \\
\text { Passive } 4\end{array}$ & $\begin{array}{l}15.32 \\
15.70\end{array}$ & $\begin{array}{l}9.01 \\
5.50\end{array}$ & $\begin{array}{l}12.08 \\
14.49\end{array}$ & $t(14)=0.77$, n.s. \\
\hline $\begin{array}{l}\text { Active } 1 \\
\text { Active } 4\end{array}$ & $\begin{array}{l}18.14 \\
10.24\end{array}$ & $\begin{array}{l}8.60 \\
4.46\end{array}$ & $\begin{array}{l}16.60 \\
11.19\end{array}$ & $t(14)=2.50, p<.025$ \\
\hline
\end{tabular}

lows that the percentage of error remained relatively constant from the 5- to 38-ft distances; the correlation between distance and percentage of error was not statistically significant for the conditions taken together, nor for any one of the conditions. Table 1 presents an analysis of the percentage of error for the active and passive groups, averaged across all nine distances.

The first three comparisons presented in Table 1 clearly support the experimental hypothesis. The group with passive experience showed no significant change in their auditory errors after $75 \mathrm{~min}$. In contrast, the active group showed a dramatic increase in accuracy: from $30.12 \%$ mean error before training to only $8.60 \%$ mean error after training $[t(14)=4.40, p<.001]$. The third comparison in Table 1 indicates that the degree of improvement in the active group was significantly greater than it was in the passive group $[t(28)=3.32, p<.005]$.

In practice, these findings mean that before active experience, a subject estimating the 23 -ft distance will err, on the average, by $7 \mathrm{ft}$. After $75 \mathrm{~min}$ of active experience, a blindfolded subject estimating the 23-ft distance will err, on the average, by less than $2 \mathrm{ft}$. This is even superior to the subjects' visual estimations.

Table 1, in the columns labeled Active 1, Active 4, Passive 1, and Passive 4, shows the comparisons of the sighted judgments before and after training. The active subjects showed a significant improvement in sighted judgments, improving from $18.14 \%$ to $10.24 \%$ mean error. In contrast, the passive subjects showed no improvement in their visual judgments.

\section{DISCUSSION}

These results indicate that the term visual deprivation is a misnomer. The subjects' auditory judgments following only $75 \mathrm{~min}$ of blindfolded activity were superior to sighted estimations prior to such activity. The subjects in the passive group showed no perceptual learning. By contrast, during the $75 \mathrm{~min}$ of active experience, the subjects changed from being highly tentative in their movements to experiencing great freedom. With verbal support from the trainer, all of the active subjects were able to engage in such activities as eating, bicycle riding, and, in one case, throwing and (almost) catching a Frisbee!
We observed that the subjects' initial distance estimations were offered very tentatively, and required some seconds for a decision to be reached. During this phase, the subject seemed to have been estimating, using a variety of analytic strategies to calculate distance. Following active experience, judgments were made spontaneously and with confidence.

What happens during the $75 \mathrm{~min}$ of activity to produce such dramatic effects? I'd like to suggest two hypotheses: (1) during training, new associations are established between auditory cues, sound sources and/or the subject's body; and (2) during training, the subject constructs a superior analogic representation of his/her spatial world. If the first hypothesis is true, then improvement should be limited to the auditory domain. This is consistent with the findings of Hein, Held, and Gower (1970), who showed that the beneficial effects of reafference upon the development of depth perception can be specific to input from one eye. If the second hypothesis is true, then the subjects should be able to use their more accurate representation to make superior visual and auditory judgments. This analogic representation hypothesis is clearly supported by the data, which shows significant improvement for the active subjects.

A theoretical interpretation in terms of an improved analogic representation is further supported by the subjects' personal accounts. The active subjects were uniformly excited about their experiences. They reported that their imaginal world seemed literally to grow around them. In one of our pilot studies, subjects answered the Betts QMI Vividness of Imagery scale before and after the 75-min period. The findings indicate an increase for the active subjects in vividness of both auditory and visual imagery.

The analogic representation hypothesis could be more directly tested by preselecting high and low scorers on the Betts QMI. Subjects with high imagery scores should profit significantly more than should those with low imagery scores.

A possible confound in the present experiment is that the active and passive groups differed both in their ability to produce auditory feedback and in the character of the sounds experienced. While the passive group listened to only one sound source at a fixed distance, the active group heard a variety of sounds coming from a variety of distances. The ideal arrangement would have the passive subjects listening to the same sounds as those experienced by the active subjects.

In future experiments, it will also be important to discover how longlasting these effects are, and whether certain types of activities during training are particularly important to perceptual learning.

\section{REFERENCES}

Bross, M., \& Borenstein, M. (1982). Temporal auditory acuity in blind and sighted subjects: A signal detection analysis. Perceptual \& $\mathrm{Mo}$ tor Skills, 55, 963-966.

CoREN, S. (1966). Adaptation to prismatic displacement as a function of the amount of available information. Psychonomic Science, 4 , 407-408.

CurTis, J. F., \& Winer, D. M. (1969). The auditory abilities of the blind as compared with the sighted. Journal of Auditory Research, 9, 57-59.

FISHER, G. H. (1964). Spatial localization by the blind. American Journal of Psychology, 77, 2-13.

Hein, A., Held, R., \& Gower, E.C. (1970). Development and segmentation of visually controlled movement by selective exposure during rearing. Journal of Comparative \& Physiological Psychology, 73, 181-187.

Held, R., \& Bossom, J. (1961). Neonatal deprivation and adult rearrangement: Complementary techniques for analyzing plastic sensorymotor coordinations. Journal of Comparative \& Physiological Psychology, 54, 33-37.

Held, R., \& HeIN, A. (1963). Movement-produced stimulation in the development of visually guided behavior. Journal of Comparative \& Physiological Psychology, 56, 872-876.

Jones, B. (1975). Spatial perception in the blind. British Journal of Psychology, 66, 461-472. 